\title{
Positive effects of the migration from Ka-band satellite to 4G solution for the communication needs of a scattered set of 1 MW solar farms in Poland: A user's experience
}

\author{
Enrique Tébar PhD ${ }^{(1)}$, Luis Hurtado ${ }^{(2)}$, Witold Bąk ${ }^{(3)}$, \\ Zbigniew Kulesza M.Sc. Eng. ${ }^{(3)}$, Andrzej Napieralski Prof. ${ }^{(3)}$
}

1. University of Alicante, Spain - Address: Carretera de San Vicente del Raspeig, s/n, 03690 San Vicente del Raspeig, Alicante, Spain - e-mail: enrique.tebar@ua.es)

2. Vodafone Spain - Address: Avenida de América 115, 28042, Madrid, Spain - e-mail: luis.hurtado@vodafone.com

3. Department of Microelectronics and Computer Science, Lodz University of Technology, Poland

Address: Wólczańska 221/223, 90-924 Łódź, Poland, e-mails: 210873@edu.p.lodz.pl, kulesza@dmcs.pl, napier@dmcs.pl

\begin{abstract}
This paper contains a concise overview of the deployment of scattered solar power plants across Poland, mainly from the perspective of their communication networks, and how the recent development of the Polish $4 \mathrm{G}$ networks has a very positive impact for the performance of the whole monitoring system (production control and video-surveillance), with a special emphasis on video-analytics, due to its higher bandwidth demand. All the information will be shown from the point of view of the solar photovoltaics developer I+D Energías, and therefore it constitutes a real user's experience.
\end{abstract}

Key words. Solar photovoltaics in Poland; scattered generation; video-analytics; 4G migration; CCTV monitoring; Ka-band; lag time.

\section{Introduction - General vision of the context}

Nowadays, it is a fact that we are experiencing an energy revolution in parallel with the fight against climate change. Because of this, the renewable energy industry and technologies have experienced a huge growth and development, at an ever faster rate over the last few years. For instance, in [1] we can check how Spanish photovoltaic companies and rural municipalities demand a sustainable and territory-friendly development of solar farms.

Currently, within the field of renewable energies, mediumsized installations linked to Medium Voltage networks are being preferred at the expense of large-sized ones associated with High Voltage infrastructures. Thus, from a distributed generation model, we need for each installation a versatile and an independent control centre to monitor the electrical production originated by the inverters and the data provided by the weather station, as well as the CCTV transmission for security purposes.

\section{Solar Photovoltaic scenario in Poland}

The demand for solar photovoltaic energy in Poland is increasing hugely every year, going from less than $20 \mathrm{MW}$ installed in 2014 to more than $3900 \mathrm{MW}$ in 2020. [2]
If we check the graph bars from the last years (mainly 2020), a huge percentage of the total capacity corresponds to micro installations under $50 \mathrm{~kW}$. But it is also true that the graycoloured area (utlity-scale solar farms coming from public auctions) adds up to a significant amount of $700 \mathrm{MW}$.

Several reasons explain this scenario, from which we can highlight the reduction in equipment costs (according to IEA's reports, the cost of solar modules was reduced by a factor of 11 between 2010 and 2020 [3]) and the European Union subsidies to make Poland, as well as the other countries that last joined the EU, reduce the volume of $\mathrm{CO}_{2}$ emissions. In fact, in order to reduce electricity prices and look for safer and alternative solutions for the environment, the government in Poland enacts a number of laws and their amendments to facilitate the construction of solar farms. [4]

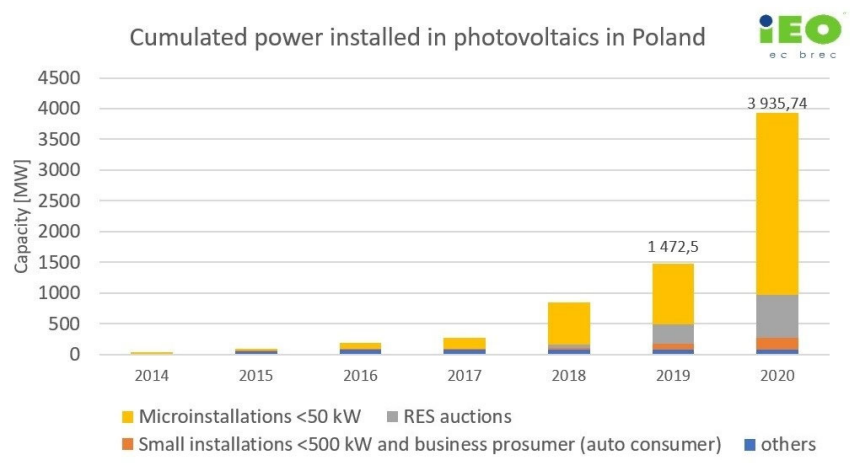

Fig. 1: Photovoltaic power installed in Poland 2014-20. [2]

State-owned companies, foreign investors with huge capital and private owners opt for solar energy as a very reliable option. Solar Photovoltaics is the most predictable renewable source, since its statistical variance is much lower than that of wind or hydro; in fact, we count with powerful software tools such as PVGIS [5] to forecast the expected solar irradiation at a specific point inside the European continent based on the characteristics of the climate of a specific region, and therefore we are able to 
estimate the expected energy gains per year. In the case of Poland, the average annual PV insolation is around 1000 $\mathrm{kWh} / \mathrm{m} 2$. Another advantage of solar power plants over wind power plants is the minor visual impact and its better landscape integration.

The Spanish company I+D Energías [6], in cooperation with its Polish company Sun Investment Group (SIG) [7] built a huge portfolio of 109 solar power plants, divided into 2 portfolios of 43 and $66 \mathrm{MW}$ respectively, for 2 different clients. The first group of power plants was built for E Energija Group (locations marked in yellow at Figure 2) and was finished in June 2019 [8], the second, built for Lords LB Asset Management (locations marked in red), was finished one year later [9]. This user's experience comes precisely from the growth of $4 \mathrm{G}$ networks between both time frames.

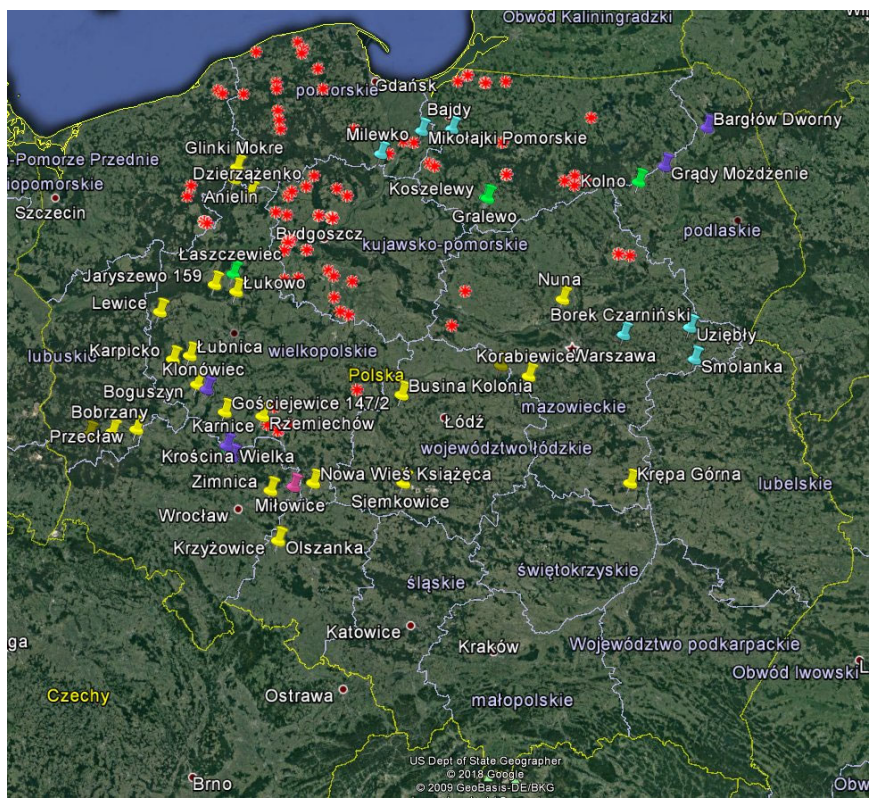

Fig.2: Map of Poland with solar farms built by $I+D$ Energías for Energija (in yellow) and Lords (in red).

\section{Evolution of 4G Networks in Poland}

In parallel with the evolution of solar photovoltaics, we must state the fact that $4 \mathrm{G}$ network in Poland has experienced a spectacular growth in rural areas (where the solar farms are installed), making it possible to obtain a global solution for the vast majority of Polish territory [10]. In fact, the $4 \mathrm{G}$ coverage maps for the different Polish operators are constantly growing according to investments and operator's deployment plans.

4G networks are also known as LTE (Long Term Evolution), the name for the standard of the 4th Generation of Mobile Wireless Communications. And they, in case of a proper coverage, can be a good option for the communication needs of the solar farms, because they need good, fast and reliable network connectivity to control and monitor CCTV images, production control, atmospheric changes (through the weather station that is also installed to monitor weather parameters), security systems and in general all the data needed for the operation of a solar farm.

The problem is that, during the construction of the first solar farms for Energija's portfolio, around the second quarter of 2018, 4G network quality on these sites was still poor, and in some cases even non-existent, so $4 \mathrm{G}$ was not an option and therefore dismissed for this portfolio, hence I+D Energías had to choose a Ka-satellite communication system, as described in the next section.

\section{Energija Dossier: Global Satellite Solution}

This Ka-satellite communication system, is composed of Satellite Antenna + LNB, Satellite Modem, Uninterruptible Power Supply and Router, as shown in Figures 3 and 4. Its provider is Skylogic, a company belonging to the European carrier Eutelsat.

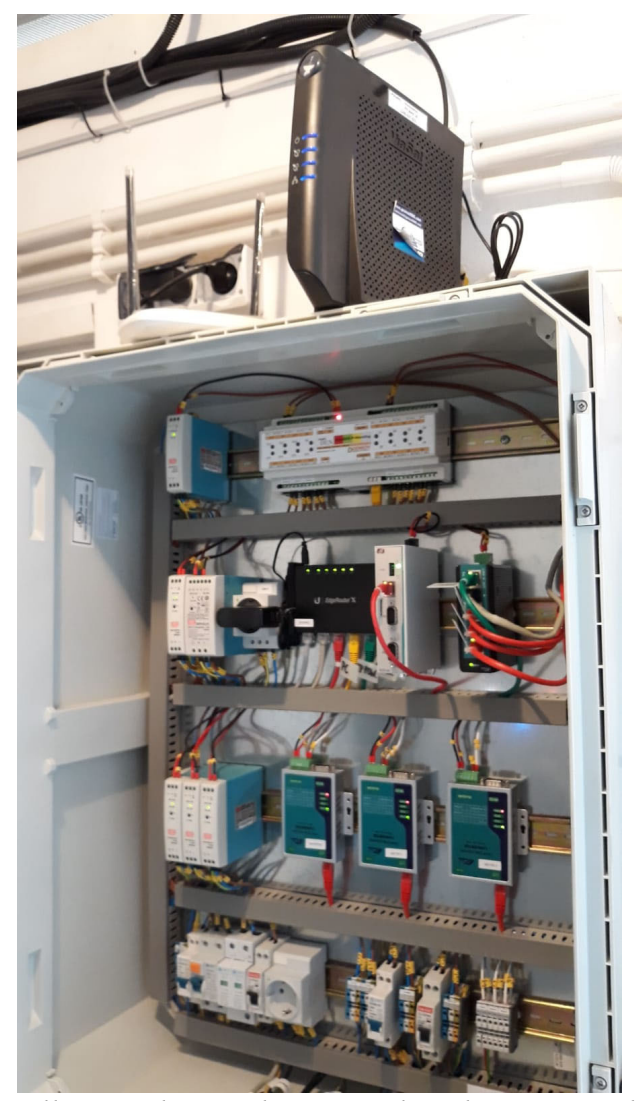

Fig.3: Satellite Modem and Router already connected to the monitoring cabinet, inside transformer station.

Satellite solutions are universal, but unfortunately quite expensive and they have a high latency time that comes to be around $800 \mathrm{~ms}$ and more. The transmission speed is very asymmetrical depending on the direction: $30 \mathrm{Mb} / \mathrm{s}$ for the downlink (reduced to $0.5 \mathrm{Mb} / \mathrm{s}$ when the $25 \mathrm{~GB}$ monthly quota is consumed) and $3 \mathrm{Mb} / \mathrm{s}$ for the uplink.

Concerning lag time, for a continuous data flow in one direction, mainly the uplink because the information is sent from the solar farm to the remote controlling user and not the other way round, this is not a problem (the information just reaches the destination $800 \mathrm{~ms}$ later), but if we need to remotely interact with the communication systems, as explained in next chapter, the lag times make the procedure very ineffective and tiresome. This effect is even worse when we need to control a lot of scattered installations, as it happens at these project portfolios developed in Poland. In fact, every $1 \mathrm{MW}$ solar farm must count with its own communication system, making the remote control more difficult than for a non-scattered PV generator, as it can be a single solar farm, on the order of several tens of megawatts, but with a single communications system to control it entirely. 


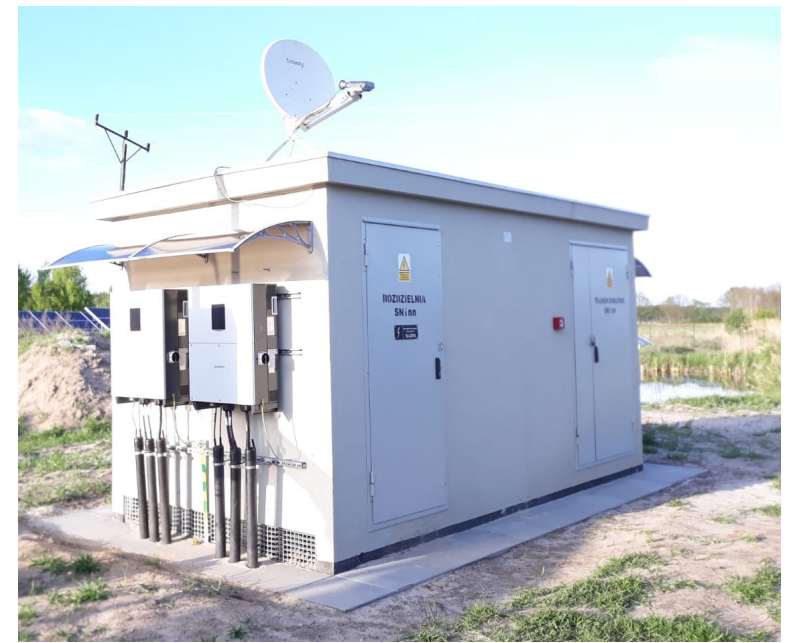

Fig.4: Satellite Antenna mounted on the top of the transformer station

Another advantage of satellite systems with respect to a $4 \mathrm{G}$ option is that satellites are in fact a dedicated link (point-topoint solution), without any kind of competence for the available bandwidth channels from other users who can suddenly be present in the area where the corresponding base station is located.

\section{Video Analytics and FLIR System}

When the technology was not as developed as at present time, the CCTV systems in general used to work under the simple observation of the screen monitoring. Nowadays, as described in [12], Video Analytics is now the Big Focus in CCTV Surveillance, even more if we must control so many installations at once in real time.

The advantages are clear: Time and money savings because less video information is sent over the network, reducing network load and storage needs, and higher efficiency because we can count with different scenario patterns depending on weather conditions, height of vegetation, existing local fauna, etc.

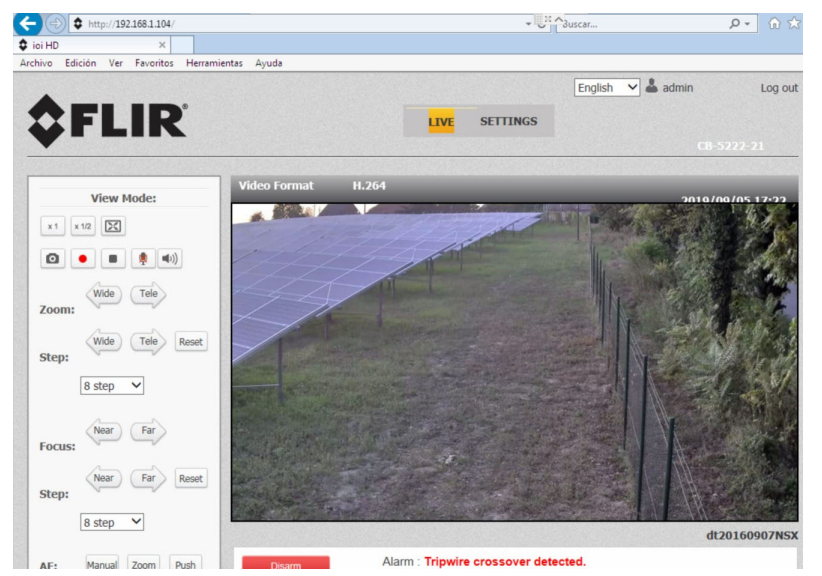

Fig.5: Screenshot of FLIR's Video Analytics System for a Solar

Farm with an alarm signal: "Tripwire crossover detected"

I+D Energías works with the CCTV Video Analytics, by using a software developed by the manufacturer FLIR [13], that can be used for own FLIR instruments and is also compatible with some other manufacturers' devices, such as Uniview (Figure 6), the one used for these projects in Poland.

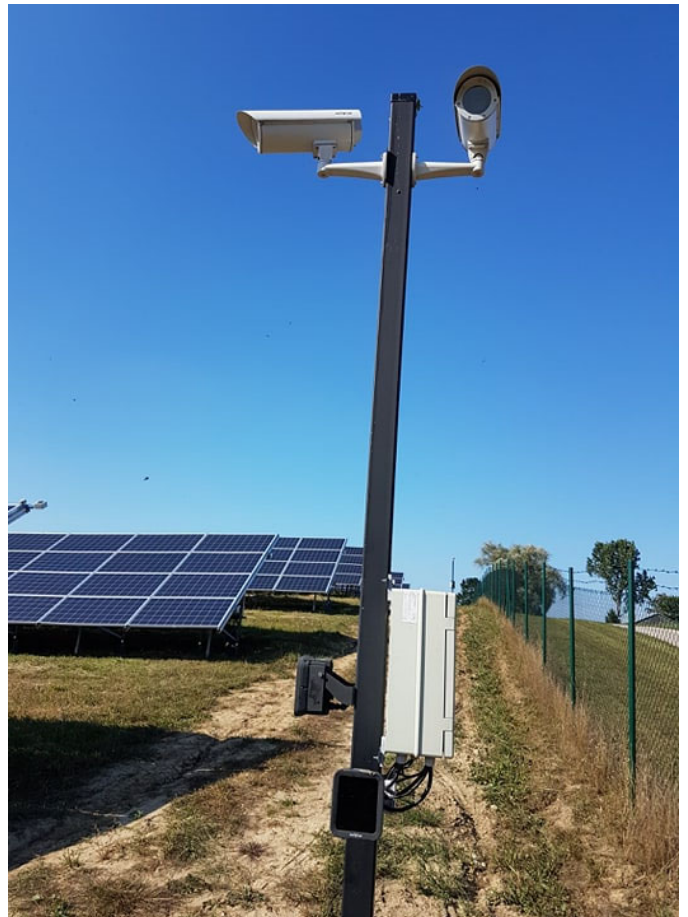

Fig.6: Uniview camera and lamp mounted over a pole for CCTV surveillance, $I+D$ Energías, Poland

As shown in Figure 5, FLIR's Video Analytics System works under a web browser, given that the cameras are IP-based technology. On the left-hand menu, we can select the different parameters for the Video Analytics: Depth, Rules, Responses and Scheduled Actions.

As described in [13], these patterns establish the usual scenarios for potential intruders: height (an animal should not be detected as a human), trajectory run by the potential intruder (a person would cross the fence and walk in a straight way), and behaviour (probably trying to hide from the cameras, whilst an animal would not behave this way), etc.

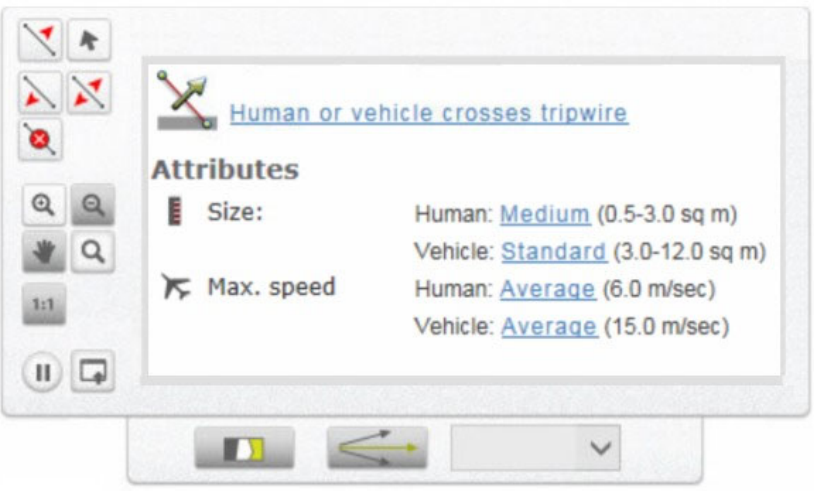

Fig.7: FLIR's Video Analytics System with the changing attributes for an intrusion

It is not the objective of this article to deepen the different configurable rules of Video Analytics, but to show the reader that a large number of configurable parameters are available. We can highlight the following ones:

- Depth tab enables CCTV system administrator define the perspective of the scene being monitored (3D view). Depth can be calibrated automatically or manually. 
Figure 8 (a) shows the definition of a multi-segment fence.

- Detection rules are a combination of one or more conditions that must be met in order to register an intruder detection (and therefore, an alarm is generated), whilst a friendly or non-intruder detection would not generate any kind of alarm. Detection rules in a defined region include: Region entrance, Loitering, Tripwire Crossover, Fence Trespassing, Stopped Vehicle and Object Removal. Figure 8 (c) to (g) shows different situations of intruder and non-intruder's detection.

- Responses and Sched. Actions screens are similar, and they include the following elements: Triggering Events (Definition of the type of event which will start the automatic response), Actions (Definition of the actions to be performed on the occurrence of a triggering event), and Schedule (When configuring automatic responses, this option enables CCTV system administrator to define when to monitor for the triggering event occurrence).

The authors want to show not only the complexity of the Video Analytics system (with a very extensive number of rules to be defined for each scenario), but also the need to make an effective and dynamic reconfiguration of these rules, not only to fine-tune the system effectiveness, but also to make it adaptive to the numerous context variations.

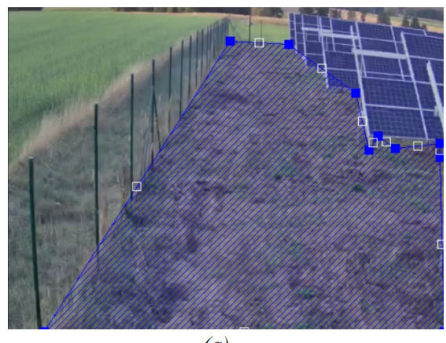

(a)

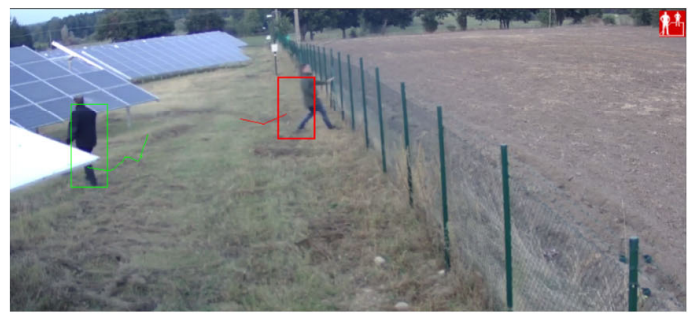

(e)

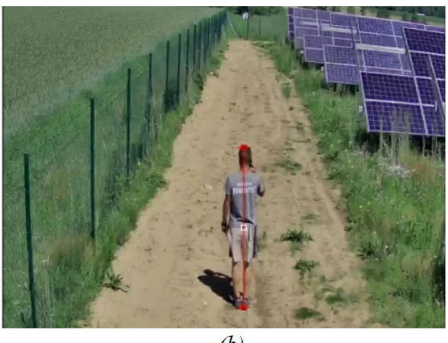

(b)

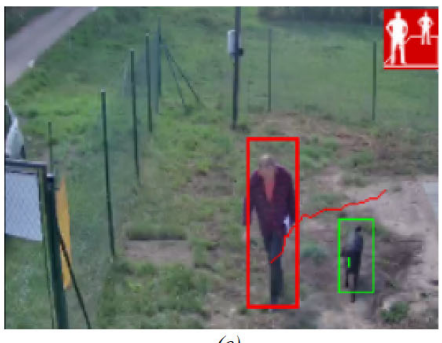

(c)

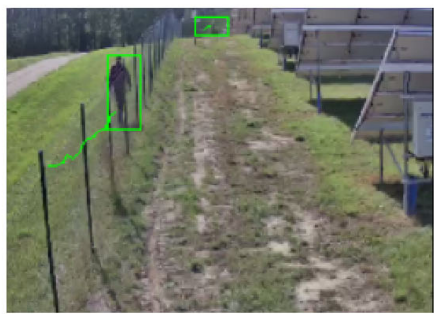

(f)

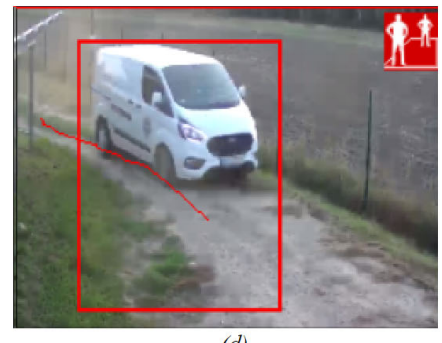

(d)

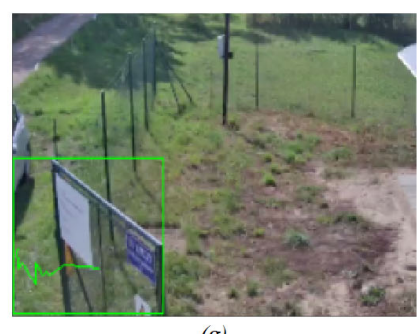

(g)

Fig.8: Definition of intrusion area (a) and intruder's height (b) in FLIR's Video analytics System. Human (red) and Animal detection (green) (c). Vehicle detection (d). Non-intruder (left, green) and Intruder detection (right, red) (e). Non-intruder, walking outside the fence (green) (f). Object movement (gate being swung by the wind) (green) (g). Source: I+D Energias's proprietary production.

In this way, high vegetation or tree crowns, linked to a homogeneous wind speed, may be misinterpreted by Video Analytics as a running intruder due to its equivalent dimensions, creating a false alarm. Besides, if the terrain is wet or snowy, the cameras may receive reflections since the terrain can act as a mirror, also creating false alarms. During night-time, for a more efficient operation of the system, we use special lamps with infrared light and ordinary lamps with white light, which we can set their operating times in accordance with our preferences. But the appearance of night moths flying around

\section{Lords Dossier: Migration to 4G}

To increase the efficiency of the Video Analytics, and to enable the system operator to change its patterns and parameters, we must quit satellite option for communications. We must therefore try $4 \mathrm{G}$ systems.

When Lords dossier started in July 2019, several field tests were made in order to verify if $4 \mathrm{G}$ option was suitable. The results were quite satisfactory and the solar farms belonging to this dossier are running on a highly directive 4G Mikrotik antenna, model SXT-2 10dbi, 60-degree, integrated 
$\mathrm{AP} /$ Backbone/CPE, dual chain, Gigabit Ethernet (Figure 9) [14], with a SIM card, instead of a satellite system.

From the economic and technical points of view, $4 \mathrm{G}$ is a cheaper solution with unsignificant lag time. However, if there are many network users in the coverage area, the range may drop to $3 \mathrm{G}$ or even $2 \mathrm{G}$, and the signal can even be completely lost. This phenomenon can have a negative impact on the proper functioning of all systems in the farm.

It is important to highlight that a few of Lords projects are running with satellite, because we cannot find a correct $4 \mathrm{G}$ network coverage alternative with any Polish $4 \mathrm{G}$ operator. But this can be considered as the lesser of two evils since it can never be as tiresome as running all the projects under a satellite link.

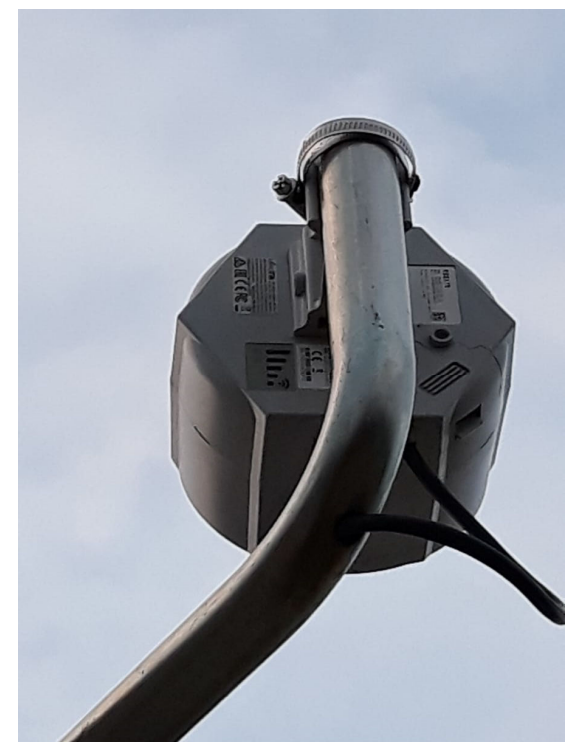

Fig.9: 10-dbi directive Mikrotik antenna to increase the $4 G$ signal level. $I+D$ Energías, Poland

\section{Comparison of costs and speed rates}

When comparing satellite and $4 \mathrm{G}$ systems costs we can see in Table 1 that in the case of satellite, the initial cost is $500 €$ per device, and the monthly fee for a 25 GB quota is $60 €$. 4Gbased technology costs are much smaller. The cost of one antenna is $75 €$, and monthly fee for an unlimited quota is $25 €$ per month.

The transmission speed rates for Ka-satellite system are 30 Mbps for downlink and $3 \mathrm{Mbps}$ for uplink (the direction in which the majority of the information is sent, because the solar farm is sending much more information than the one received). For $4 \mathrm{G}$ system, the results obtained after running speed tests at the different locations are better for our main purpose (around 5 Mbps for uplink).

In both cases, rates are certainly sufficient to monitor and control solar farms with the sole and important exception of lag time and its negative effects on real-time remote Video Analytics controlling, as explained in previous chapters.
Table 1

\begin{tabular}{|c|c|c|}
\hline \multicolumn{3}{|c|}{$\begin{array}{l}\text { Comparison of costs and speed rates (average of } \\
\text { several tests) for } 4 \mathrm{G} \text { and Ka-satellite technologies }\end{array}$} \\
\hline $\begin{array}{c}\text { Communications } \\
\text { type }\end{array}$ & $4 G$ & Ka-satellite \\
\hline Initial cost for device & $75 €$ & $500 €$ \\
\hline Monthly fee & $25 \epsilon$ & $60 €$ \\
\hline $\begin{array}{c}\text { Monthly high-speed } \\
\text { quota }\end{array}$ & Unlimited & $25 G B$ \\
\hline Download rate & $25 M_{b p s} s^{(l)}$ & $30 \mathrm{Mbps}$ \\
\hline Upload rate & $5 M_{b p s^{(l)}}$ & 3 Mbps \\
\hline $\begin{array}{c}\text { Lag time } \\
\text { (Typical value) }\end{array}$ & $20 \mathrm{~ms}$ & $800 \mathrm{~ms}$ \\
\hline
\end{tabular}

\section{Conclusions}

The 4G LTE networks are exponentially becoming more and more efficient, thus relying on them for monitoring communication systems in rural area locations (as happens to be our case with solar farms) in place of Ka satellite systems will progressively become more and more usual. It will also depend on local conditions and the speed and coverage growth of $4 \mathrm{G}$ operators, as well as the working frequency bands ${ }^{1}$. In Poland's case, the signal has strengthened and stabilised, and the connectivity has a larger range, covering almost the entire country.

In addition, as checked on site by our user's experience, $4 \mathrm{G}$ networks are cheaper to install and maintain than satellite systems and their exponential growth is hugely positive for the effective monitoring of scattered PV generators, a key factor for the distributed production. This is an advantageous option, not only from the cost-saving due to lower transmission losses but also in terms of usual redundancy and reliability, since distributed systems have the potential to supply electricity during power-grid outages resulting from extreme weather, other natural catastrophes, or emergency situations, reducing blackouts or the adverse effects of terrorism. [15]

However, satellite systems can also work synchronised with 4G LTE networks, where we can divide the transmitted information for a specific system. E.g. the $4 \mathrm{G}$ network can be responsible for the data collected from video surveillance (much higher bitrate needs), and the satellite system can be responsible for other data with no interaction needs, such as production control or figures retrieved by the weather station. Another variant of the solution is to use the satellite infrastructure as backup systems only, whilst $4 \mathrm{G}$ can be mainly used to collect information.

${ }^{1}$ Lower frequencies (Around $800 \mathrm{MHz}$ ) are more suitable for rural environments (our case), where the density of Base Stations decreases in comparison to urban settings $(2600 \mathrm{MHz})$, given that the lower the frequency, the higher the wave propagation and therefore the bigger the area covered. 
Table 2

\begin{tabular}{|c|c|c|c|}
\hline \multicolumn{4}{|c|}{$\begin{array}{c}\text { Set of parameters for the different existing } \\
\text { technologies of Mobile Wireless Communications }\end{array}$} \\
\hline $\begin{array}{c}\text { Kind of } \\
\text { technology }\end{array}$ & $\begin{array}{c}\text { Value max. } \\
\text { Downlink (1) }\end{array}$ & $\begin{array}{c}\text { Value max. } \\
\text { Uplink (1) }\end{array}$ & $\begin{array}{c}\text { Latency } \\
\text { (Typical value) }\end{array}$ \\
\hline $\begin{array}{c}\text { Real needs of PV } \\
\text { farm system }\end{array}$ & $128 \mathrm{kbps}$ & $10 \mathrm{Mbps}$ & $\begin{array}{c}\text { As low as } \\
\text { possible for } \\
\text { interaction } \\
\text { purposes }\end{array}$ \\
\hline Satellite & $20 \mathrm{Mbps}$ & $6 \mathrm{Mbps}$ & $600 \mathrm{~ms}$ \\
\hline $5 \mathrm{G}$ & $10-20 \mathrm{Gbps}$ & $1-10 \mathrm{Gbps}$ & $1 \mathrm{~ms}$ \\
\hline $\begin{array}{c}\text { 4G+ (LTE-A } \\
\text { CAT 16) }\end{array}$ & $700-1000$ & $50+\mathrm{Mbps}$ & $20 \mathrm{~ms}$ \\
\hline $4 \mathrm{G}$ (LTE CAT 4) & $150 \mathrm{Mbps}$ & $50 \mathrm{Mbps}$ & $40 \mathrm{~ms}$ \\
\hline $3 \mathrm{G}$ (DC-HSPA+) & $42.2 \mathrm{Mbps}$ & $8 \mathrm{Mbps}$ & $100-500 \mathrm{~ms}$ \\
\hline 2G (EDGE) & $300 \mathrm{kbps}$ & $100 \mathrm{kbps}$ & $300-1000 \mathrm{~ms}$ \\
\hline
\end{tabular}

(1) Lab conditions: Maximum available resources, optimal environment.

Table $2[16,17]$ does not include information on the future 6th Generation of Mobile Wireless Communications, given that the joint of telecommunications standard development organizations (ARIB, ATIS, CCSA, ETSI, TSDSI, TTA, TTC), to produce the Reports and Specifications from $3 \mathrm{G}$ and beyond, also known as 3GPP (3rd Generation Partnership Project) [18] has not yet defined the $6 \mathrm{G}$ standard, as well as its specifications, capabilities and timelines.

In terms of security, thanks to the point-to-point beam of the satellite system it makes it difficult for indirect relays to hack or steal private information. But neither is $4 \mathrm{G}$ network security compromised since it adds encryption processes in the control and data planes, as well as complex key exchange procedures for network access authentication and authorization, among others.

Another very important $4 \mathrm{G}$ network advantage is their reduced lag time, enabling an easy remote interaction from a system supervisor, mainly to control Video Analytics in a dynamic way. Based on this, I+D Energías has also been changing existing Energija installations from Ka-satellite to $4 \mathrm{G}$ over the last months.

Finally, it is relevant to specify that although this article describes the user experience specifically in Poland, it is scalable to any location where $4 \mathrm{G}$ evolution and deployments are advanced enough to take advantage of the technical benefits and apply them to a distributed generation of photovoltaic energy.

\section{Acknowledgement}

The authors would like to thank Mr. Benigno López, Mr. Francisco Blasco and Mr. David Magán for their helpful support and advice on various technical issues examined in this paper, as well as Mr. Nicolás Ellarby for his support in the revision of the English grammar and orthography.

\section{References}

[1] AVAESEN (Energy Management Board of the Valencian Region in Spain) launches a manifesto for the rational development of renewable energies in the Valencian Community:

https://www.agronewscomunitatvalenciana.com/avaesen-lanza-unmanifiesto-por-el-desarrollo-racional-de-las-energias-renovables-en-lacomunitat

[2] Photovoltaics in Poland 2020 summary by IEO (Polish Institute for Renewable Energies):

https://www.ieo.pl/en/86-en/news/1522-photovoltaics-in-poland-2020summary-by-ieo

[3] International Energy Agency (IEA). Evolution of solar PV module cost by data source, 1970-2020:

https://www.iea.org/data-and-statistics/charts/evolution-of-solar-pv-modulecost-by-data-source-1970-2020

[4] Act about Renewable Sources in Poland: http://prawo.sejm.gov.pl/isap.nsf/download.xsp/WDU20170001148/U/D 20171148Lj.pdf (in Polish)

[5] European Commission, Photovoltaic Geographical Information System: https://re.jrc.ec.europa.eu/pvg_tools/en/tools.html

[6] https://www.idenergias.com/quienes-somos

[7] https://suninvestmentgroup.com/a-renewable-energy-company/

[8] https://www.pb.pl/litwini-duzo-postawili-na-polskie-slonce-933041 (in Polish)

[9] https://lordslb.lt/eiffel-energy-transition-to-finance-the-construction-of66-solar-parks-with-a-total-capacity-of-65-5-mw-in-poland

[10] https://www.tabletowo.pl/play-podsumowanie-2018-roku-plany-nanastepne-lata-strategia/

[11] https://www.play.pl/pomoc/mapa-zasiegu.html

[12] Ainsworth P: 5 Reasons Why Video Analytics is now the Big Focus in CCTV Surveillance, IFSEC Global: https://www.ifsecglobal.com/videosurveillance/5-reasons-why-video-analytics-is-now-the-dominant-techin-cctv-surveillance/

[13] FLIR Systems, Inc: ioi User Guide, HTML Edition Units, ver.1, Nov 2016: https://www.flir.com/globalassets/imported-assets/document/flirioi-html-edition-units-user-guide-en.pdf

[14] https://mikrotik.com/product/RBSXTG-2HnDr2-168

[15] Mehto V., Phadke B.N.: Distributed PV Systems an Advantage, IOSRJEEE, Vol. 12, Issue 2 Ver. II, DOI: 10.9790/1676-1202021419

[16] https:/www.gsma.com/futurenetworks/wpcontent/uploads/2015/01/Understanding-5G-Perspectives-on-futuretechnological-advancements-in-mobile.pdf

[17] https://5gobservatory.eu/info-deployments/5g-performance/

[18] 3GPP (3rd Generation Partnership Project): https://www.3gpp.org/ 